\title{
Heterogeneity of Green TFP in China's Logistics Industry under Environmental Constraints
}

\author{
Fan Liu (iD) ${ }^{1}$ and Han Xu (iD ${ }^{1,2}$ \\ ${ }^{1}$ School of Business Administration, Zhongnan University of Economics and Law, Wuhan 430073, China \\ ${ }^{2}$ Business School, Wuchang University of Technology, Wuhan 430223, China \\ Correspondence should be addressed to Han Xu; coldxu520@163.com
}

Received 21 September 2020; Revised 23 October 2020; Accepted 28 October 2020; Published 12 November 2020

Academic Editor: Wei Zhang

Copyright (C) 2020 Fan Liu and Han Xu. This is an open access article distributed under the Creative Commons Attribution License, which permits unrestricted use, distribution, and reproduction in any medium, provided the original work is properly cited.

\begin{abstract}
In the context of China's supply-side structural reform and the concept of green development, we introduce the energy and environmental factors into the analytical framework of the total factor productivity (TFP) of the logistics industry and use the Global Malmquist-Luenberger index method to analyze the evolution trend and heterogeneity of green TFP in the logistics industry of 30 provinces (cities and districts) in China from 2003 to 2017. The results show that, firstly, the green TFP and traditional TFP of China's logistics industry are both on the rise and the absence of energy and environmental factors will lead to the overestimation of TFP of the logistics industry. Whether it is green TFP or traditional TFP, the main source of its growth is technical progress. Secondly, there is obvious regional heterogeneity in green TFP of logistics industry. Under the three regional division standards, the average annual growth rate of green TFP is from high to low in the order of eastern, western, and central regions. Under the eight regional classification standards, the eastern coastal economic zone, the southern coastal zone, the northern coastal zone, the northeast region, the middle reaches of the Yellow River, the southwest region, the middle reaches of the Yangtze River, and the northwest region are in order from high to low. Thirdly, there is obvious interprovincial heterogeneity in green TFP of the logistics industry. The highest growth rate of green TFP is in Zhejiang, followed by Jiangsu and Guangdong, and the slowest growth rate is in Chongqing. The technical progress of logistics industry in most provinces contributes more to the growth of green TFP. Fourthly, the differences of green TFP in the three regions of the east, center, and west are shrinking, which may be $\sigma$ convergence, but the differences among the three regions are expanding. Compared with the existing literature, this paper applies the measurement framework of green TFP to China's logistics industry and investigates the regional and provincial heterogeneity of green TFP in logistics industry. The conclusions are significant to understand and grasp the heterogeneity of green TFP growth in China's logistics industry under environmental constraints and how to promote the development of green logistics in China.
\end{abstract}

\section{Introduction}

Since the beginning of the new century, China's logistics industry has been developing rapidly. The added value of the industry has gradually increased from 616.19 billion yuan in 2000 to 4280.21 billion yuan in 2019 , with an average annual growth rate of $10.7 \%$ (data source: National Bureau of Statistics). The logistics industry in this paper refers to the transportation, storage, and postal industry in the "National Economic Industry Classification." However, the rapid development of the logistics industry has also brought great negative externalities to the society, and the problems of energy consumption and pollutant emission caused by its economic activities have become increasingly prominent. National statistics show that, in 2017, the terminal energy consumption of the logistics industry reached as high as 421.191 million tons of standard coal, accounting for $9.41 \%$ of the total national energy consumption and far exceeding the $4.46 \%$ of its added value in GDP. It can be seen that the problem of energy consumption caused by the production activities of China's logistics industry is becoming increasingly serious, and the $\mathrm{CO}_{2}$ emission caused by it cannot 
be ignored. In the context of low-carbon economy and green development in the new era, reducing energy consumption and pollutant emission is not only a part of the theme of ecological civilization construction, but also a mandatory requirement of sustainable economic development [1-3]. In fact, China faces enormous pressure on carbon emission reduction. Therefore, China has set the ambitious goal of reducing $\mathrm{CO}_{2}$ emissions per unit of GDP by $17 \%$ in the 12 th Five-Year Plan. In order to reduce carbon emissions and achieve the stable economic growth, it is necessary to transform into a "resource-saving and environmentfriendly" society. The transformation of economic growth mode from extensive form to intensive form is imminent. In this context, low-carbon economy is increasingly becoming a hotspot in the world. The development of low-carbon economy is in line with China's basic national policy of implementing sustainable development strategy and building a harmonious society. Low-carbon economy has gradually become a "new normal" of China's economic growth. Similar to the situation faced by the industrial industry, the service sector such as the logistics industry should adhere to the concept of green development while stimulating economic growth, to minimize the negative impact of industrial development on resources and environment $[4,5]$. How to realize the green growth of logistics industry is a difficult problem for China, and the effective way to solve this problem is to improve the green total factor productivity (green TFP) of logistics industry [6,7]. Green TFP is an effective indicator to measure the quality of economic growth. Compared with the traditional total factor productivity (TFP) mentioned later, green TFP can scientifically reflect the energy consumption and undesired output of economic activities, which is a better explanation for economic growth performance. Therefore, we introduce the energy and environmental factors into the measurement framework of total factor productivity of logistics industry, measure the green TFP of this industry, and compare and analyze it with the traditional TFP. On this basis, empirical analysis of the regional heterogeneity and interprovincial heterogeneity of the TFP change, in addition to the evolution trend characteristics of regional differences. This study is not only conducive to evaluate the green growth performance of the logistics industry, but also conducive to analyze the regional differences and evolution of the growth of green TFP of the logistics industry. This paper is of great practical significance for China to formulate reasonable development policies and promote the green growth of the logistics industry.

The logistics industry is an important sector of the service industry. However, the current academic research on the total factor productivity of the logistics industry is relatively limited and mainly focuses on its traditional productivity. Jing et al. [8] estimated the traditional TFP of the logistics industry based on C-D production function and found that the TFP index of the logistics industry in different regions is significantly different, which is mainly attributed to the regional differences of input factors such as capital and technology. Chen [9] used the Malmquist index to evaluate the traditional TFP of
China's logistics industry, and the results showed that the traditional TFP of the logistics industry decreased by $2.4 \%$ annually from 2005 to 2009 , and the deterioration of pure technical efficiency was the source of the decline of TFP. At the same time, the traditional TFP growth rate of logistics industry presented the situation of east, middle, and west decreasing in turn. In recent years, some scholars have begun to pay attention to the energy and environmental problems of the logistics industry. For example, Jiang et al. [10] measured the total factor of energy efficiency of the logistics industry by using the super-efficiency nonexpected SBM model. Unfortunately, the current research on green TFP of China's logistics industry is still insufficient. In addition, scholars began to analyze the evolution trend or convergence of TFP in the service sector. For example, Yuan et al. [11] found that the subsectors of producer services show a trend of $\sigma$ convergence, while absolute $\beta$ and conditional $\beta$ convergence exist within sectors. Xiao [12] also analyzed the convergence of traditional and green TFP in the service industry and found that the two types of TFP subsectors of China's service industry had only conditional $\beta$ convergence but not absolute $\beta$ convergence characteristics. During this period, scholars also made a preliminary discussion on the TFP convergence of the logistics industry, an important service sector. Studies such as Jing et al. [8] show that there is no $\sigma$ convergence in the traditional TFP of China's logistics industry.

The previous literature has provided the possibility for this study, but there are still some deficiencies in the following aspects. Firstly, the existing studies are almost all to investigate the changes of traditional TFP in China's logistics industry, and the green TFP measurement research in the logistics industry under the constraints of energy and environment is lacking now, while the logistics industry has generated very serious environmental problems. Therefore, the traditional TFP cannot truly reflect the actual situation of TFP in the current logistics industry. Secondly, there are few literatures about the productivity convergence of logistics, but the TFP of China's logistics varies greatly, so it is necessary to study the evolution trend of its productivity, especially the green TFP. Thirdly, the existing studies have divided China into three regions, east, middle, and west, which cannot fully reflect the differences in the TFP growth of the logistics industry in the subdivided economic zones (such as the eight economic zones). In view of the above problems, the marginal contribution of this study includes the following. Firstly, we use the Global Malmquist-Luenberger index to estimate the green TFP in the logistics industry of 30 provinces (cities and districts) in China from 2003 to 2017 and compare it with the traditional TFP without considering the energy and environment constraints. Secondly, we study the regional and interprovincial heterogeneity of green TFP in logistics industry on the basis of overall analysis. Thirdly, when we analyze the evolution trend of green TFP in logistics industry on the basis of national level, we not only start from the traditional three regions of east, middle, and West, but also further analyze based on the eight economic regions. 


\section{Measurement Methods, Variables, and Data}

\subsection{Measurement Methods}

2.1.1. Current and Global Production Possibilities Set. First, we need to build a set of production possibilities, called environmental technologies. This production probabilities set includes both "good" outputs such as GDP and "bad" outputs such as $\mathrm{CO}_{2}$ emissions [13-15]. Suppose that, in different periods $t(t=1, \ldots, T)$, the logistics industry in any province $k(k=1, \ldots, K)$ uses $N$ kinds of inputs $x=\left(x_{1}, \ldots, x_{N}\right) \in R_{N}^{+}$to produce $M$ kinds of "good" outputs $y=\left(y_{1}, \ldots, y_{M}\right) \in R_{M}^{+}$and $I$ kinds of "bad" outputs $b=\left(b_{1}, \ldots, b_{I}\right) \in R_{I}^{+}$. For each input vector $x$, environmental technologies can produce a combination of expected and unexpected outputs simultaneously $(y, b)$. Based on the hypothesis of Wang et al. [16], we use the data envelopment analysis (DEA) method to convert the current environmental technology into

$$
P^{t}\left(x^{t}\right)=\left\{\begin{array}{c}
\left(y^{t}, b^{t}\right): \sum_{k=1}^{K} z_{k}^{t} y_{k m}^{t} \geq y_{k m}^{t}, \quad m=1, \ldots, M \\
\sum_{k=1}^{K} z_{k}^{t} b_{k i}^{t}=b_{k i}^{t}, \quad i=1, \ldots, I, \\
\sum_{k=1}^{K} z_{k}^{t} x_{k n}^{t} \leq x_{k n}^{t}, \quad n=1, \ldots, N, \\
z_{k}^{t} \geq 0, \quad k=1, \ldots, K .
\end{array}\right\} .
$$

In (1), $z_{k}^{t}$ is the weight measurement index of the observed values of each cross section and $z_{k}^{t} \geq 0$ means the constant returns to scale. When measuring GML index, the current production possibility set $P^{t}\left(x^{t}\right)$ should be replaced by the global production possibility set $P^{G}(x)$, which can be expressed as formula (2) with DEA method:

$$
P^{t}\left(x^{t}\right)=\left\{\begin{array}{c}
\left(y^{t}, b^{t}\right): \sum_{t=1}^{T} \sum_{k=1}^{K} z_{k}^{t} y_{k m}^{t} \geq y_{k m}^{t}, \quad m=1, \ldots, M, \\
\sum_{t=1}^{T} \sum_{k=1}^{K} z_{k}^{t} b_{k i}^{t}=b_{k i}^{t}, \quad i=1, \ldots, I, \\
\sum_{t=1}^{T} \sum_{k=1}^{K} z_{k}^{t} x_{k n}^{t} \leq x_{k n}^{t}, \quad n=1, \ldots, N, \\
z_{k}^{t} \geq 0, \quad k=1, \ldots, K .
\end{array}\right\} .
$$

2.1.2. SBM Directional Distance Function. According to Fukuyama and Weber [17], the global SBM directional distance function incorporated into $\mathrm{CO}_{2}$ emissions in the logistics industry is expressed as

$$
\begin{gathered}
S_{V}^{G}\left(x^{t, k^{\prime}}, y^{t, k^{\prime}}, b^{t, k^{\prime}}, g^{x}, g^{y}, g^{b}\right)=\max _{s^{x}, s^{y}, s^{b}} \frac{1 / N \sum_{n=1}^{N}\left(s_{n}^{x} / g_{n}^{x}\right)+(1 /(M+I))\left(\sum_{m=1}^{M}\left(s_{m}^{y} / g_{m}^{y}\right)+\sum_{i=1}^{I}\left(s_{i}^{b} / g_{i}^{b}\right)\right)}{2}, \\
\text { s. t. } \sum_{t=1}^{T} \sum_{k=1}^{K} z_{k}^{t} x_{k n}^{t}+s_{n}^{x}=x_{k^{\prime} n}^{t}, \quad \forall n, \\
\sum_{t=1}^{T} \sum_{k=1}^{K} z_{k}^{t} y_{k m}^{t}-s_{m}^{y}=y_{k^{\prime} m}^{t}, \quad \forall m, \\
\sum_{t=1}^{T} \sum_{k=1}^{K} z_{k}^{t} b_{k i}^{t}+s_{i}^{b}=x_{k^{\prime} i}^{t}, \quad \forall i, \\
\sum_{k=1}^{K} z_{k}^{t}=1, z_{k}^{t} \geq 0, \quad \forall k ; \\
s_{n}^{x} \geq 0, \quad \forall n, \\
s_{m}^{y} \geq 0, \quad \forall m,
\end{gathered}
$$


In (3), $\left(x^{t, k^{t}}, y^{t, k^{t}}, b^{t, k^{t}}\right)$ is the input and output vector of logistics industry in province $k$. $\left(g^{x}, g^{y}, g^{b}\right)$ is a direction vector, which represents the decrease of input, the increase of "good" output, and the decrease of "bad" output. $\left(s_{n}^{x}, s_{m}^{y}, s_{i}^{b}\right)$ is a relaxation vector reflecting the input and output. If the relaxation vectors of both inputs and outputs are positive numbers greater than 0 , it means that the actual input and carbon emission of logistics industry in each province are larger than the input-output value of the boundary, while the actual output value is smaller than the boundary output value. To sum up, $s_{n}^{x}, s_{m}^{y}, s_{i}^{b}$ represents the situation of excessive input, relatively insufficient "good" output, and excessive pollution emissions in the logistics industry of each province [16].
2.1.3. Global Malmquist-Luenberger Productivity Index. After the construction of the SBM directional distance function, we need to construct output-oriented GML index to measure green TFP. According to Oh [18], the GML index can be expressed as

$$
\mathrm{GML}_{t}^{t+1}=\frac{1+S_{C}^{G}\left(x^{t}, y^{t}, b^{t} ; g\right)}{1+S_{C}^{G}\left(x^{t+1}, y^{t+1}, b^{t+1} ; g\right)}
$$

Furthermore, the GML index can be divided into two parts: the efficiency change index (GEC) and the technology change index (GTC):

$$
\mathrm{GML}_{\mathrm{t}}^{t+1}=\frac{1+S_{C}^{t}\left(x^{t}, y^{t}, b^{t} ; g\right)}{1+S_{C}^{t+1}\left(x^{t+1}, y^{t+1}, b^{t+1} ; g\right)} \times\left[\frac{\left(1+S_{C}^{G}\left(x^{t}, y^{t}, b^{t} ; g\right)\right) /\left(1+S_{C}^{t}\left(x^{t}, y^{t}, b^{t} ; g\right)\right)}{\left(1+S_{C}^{G}\left(x^{t+1}, y^{t+1}, b^{t+1} ; g\right)\right) /\left(1+S_{C}^{t+1}\left(x^{t+1}, y^{t+1}, b^{t+1} ; g\right)\right)}\right] .
$$

When the $\mathrm{GML}_{t}^{t+1}$ (GEC or GTC) index is greater than 1, the green TFP (technical efficiency or technical progress) of the logistics industry shows an increasing trend. When the index is equal to (or less than) 1, the green TFP (technical efficiency or technical progress) remains unchanged (or decreases).

$$
\operatorname{GM}\left(y^{t+1}, x^{t+1}, y^{t}, x^{t}\right)=\frac{D^{t+1}\left(x^{t+1}, y^{t+1}\right)}{D^{t}\left(x^{t}, y^{t}\right)}\left[\left(\frac{D^{g}\left(x^{t+1}, y^{t+1}\right)}{D^{t+1}\left(x^{t+1}, y^{t+1}\right)} \times \frac{D^{t}\left(x^{t}, y^{t}\right)}{D^{g}\left(x^{t}, y^{t}\right)}\right)\right]=\mathrm{EC} \times \mathrm{TC} .
$$

For the reelated materials of the decomposition methods, refer to Ang [19], Ang and Liu [20], Zhang et al. [21], Zhang et al. [22], Wang et al. [23], and Zhang et al. [24].

2.2. Variable Selection and Data Sources. We collected the input-output data of the logistics industry from 2003 to 2017 in 30 provinces, autonomous regions, and municipalities in China (Tibet is not included as a sample due to a large amount of missing data). We took capital, labor, and energy as input indicators and the added value and $\mathrm{CO}_{2}$ emissions as "good" output and "bad" output, respectively. The data are collected from the website of the National Bureau of Statistics, China Statistical Yearbook, and China Energy Statistical Yearbook.

2.2.1. Logistics Output: "Good Output". Learning from Chen [9], we regard the added value of the logistics industry as a "good" output and use the added value index of the tertiary industry of each province to convert it into real value (2003 as the base period).
2.1.4. Global Malmquist Productivity Index. In order to more intuitively reflect the constraints of environmental factors such as energy and pollution emissions on China's logistics industry, we also estimate the traditional TFP of this industry and apply the DEA-Malmquist productivity index method (Global Malmquist index method) based on the Global technology and compare it with the GML index. The Global Malmquist index can be expressed as
2.2.2. Logistics Output: "Bad Output". At present, there is no uniform definition of "bad" output in the academic circles, and the "bad" output adopted in measuring green TFP is also different. We measure a total factor green productivity index considering $\mathrm{CO}_{2}$ emissions, so we take $\mathrm{CO}_{2}$ emissions as "bad" output. $\mathrm{CO}_{2}$ emissions of logistics industry can be calculated by the following formula:

$$
\mathrm{CO}_{2}=\sum_{i=1}^{8} \mathrm{CO}_{2, i}=\sum_{i=1}^{8} E_{i} \times \mathrm{NCV}_{i} \times \mathrm{CEF} \times \mathrm{COF}_{i} \times \frac{44}{12}
$$

Among them, $i$ is the type of final energy consumption (fossil fuels); $E_{i}$ represents the consumption of type $i$ fossil fuels. $\mathrm{NCV}_{i}$ represents the low calorific value of type $i$ fossil fuels. $\mathrm{CEF}_{i}$ is the carbon content of type $i$ fossil fuels. $\mathrm{COF}_{i}$ is the oxidation rate of type $i$ fossil fuels. Accordingly, the carbon emission coefficient calculation formula of various fossil fuels can be obtained: carbon emission coefficient $=$ low calorific value $\times$ carbon content $\times$ oxidation rate. The carbon emission coefficients for each type of fossil fuels are shown in Table 1. 
TABle 1: The carbon emission coefficients for each type of fossil fuels.

\begin{tabular}{lcccc}
\hline Fossil fuel type & Low calorific value & Carbon content & Oxidation rate & Carbon emission coefficient \\
\hline The raw coal & 20908 & 26.4 & 0.94 & 0.5183 \\
Coke & 28435 & 29.5 & 0.93 & 0.7801 \\
Crude oil & 41816 & 20.1 & 0.98 & 0.8237 \\
Gasoline & 43070 & 18.9 & 0.98 & 0.7978 \\
Diesel & 42652 & 20.2 & 0.98 & 0.8443 \\
Fuel oil & 41816 & 21.1 & 0.98 & 0.8647 \\
Natural gas & 38931 & 15.3 & 0.99 & 0.5897 \\
Kerosene & 43070 & 19.5 & 0.98 & 0.8231 \\
\hline
\end{tabular}

Compiled according to China Energy Statistics Yearbook.

2.2.3. Capital Investment. We use the capital stock of logistics industry in each province to express the capital investment and use the perpetual inventory method to estimate it:

$$
K_{i t}=K_{i, t-1}\left(1-\delta_{i, t}\right)+\frac{I_{i t}}{P_{i t}}
$$

In (8), $K_{i t}$ and $K_{i, t-1}, I_{i, t}$, respectively, represent the capital stock of $t$ year and $t-1$ year and the nominal fixed capital investment of $t$ year of the logistics industry in province $i . \delta_{i, t}$ is the capital depreciation rate, and $P_{i t}$ is the price indices of fixed assets investment. The base year capital stock adopts the steady-state method proposed by Harberger [25]. Based on the assumption that "the ratio of capital output in steady state is constant or the growth rate of physical capital is equal to the growth rate of total output," the estimation formula of the physical capital stock in the base year (2003) is deduced:

$$
K_{i, t-1}=\frac{I_{i, t}}{\left(g_{i, t}+\delta_{i, t}\right)} .
$$

This method has a clear and reasonable economic basis, so it has been applied widely, such as Lee and Hong [26], Barro and Lee [27], and $\mathrm{Wu}$ [28]. Meanwhile, according to Harberger's suggestion [25], $g_{i, t}$ is expressed in terms of the average annual growth rate of the real added value of the logistics industry in the sample period to control the impact of the economic cycle fluctuations and short-term output fluctuations. Nominal fixed capital investment $I_{i, t}$ represented fixed assets investment of the whole society. Subject to limited data, $P_{i t}$ is represented by the industry-wide fixed asset investment price index. In accordance with the existing studies, the depreciation rate $\delta_{i, t}$ was set at $6 \%$, but the $4 \%$ and $9.6 \%$ depreciation rates were also adopted for robustness tests.

2.2.4. Labor Input. Theoretically, labor input should comprehensively consider factors such as labor size, labor time, and labor quality (efficiency), but the selection of indicators in actual research will ultimately depend on the availability of data. In fact, some scholars have considered the quality of labor input in their studies. For example, Fox and Smeets proposed four methods to measure the labor quality when using Danish enterprise level data to examine whether the input quality affects the enterprise productivity dispersion
[29]. Zheng et al. adjusted the quality of labor by using the number of years of education per worker while examining China's growth model [30]. In order to consider the impact of the labor input quality on results, we also try to adjust the quality of the number of employees of the logistics industry in each region. Unfortunately, the relevant data on the quality adjustment of labor input cannot be accessed through the existing statistical data, no matter which method is adopted. Therefore, the "number of employees at the end of the year" of logistics industry is selected as the proxy variable of labor input index.

2.2.5. The Energy Input. As energy resource is an intermediate input, the traditional TFP of logistics industry has not been regarded as an input variable in the existing research. However, energy consumption is in fact the key factor to undesirable outputs such as $\mathrm{CO}_{2}$ emissions [16]. Based on this, we also introduced energy into the green TFP measurement system and adopted the terminal energy consumption of the logistics industry in each province as the measurement index of this variable. The basic data were taken from the China Energy Statistics Yearbook.

Table 2 reports the descriptive statistical results for each variable.

\section{Temporal Characteristics and Heterogeneity Analysis of Green TFP in Logistics Industry}

3.1. Overall Temporal Characteristics. Table 3 reports the TFP index and its decomposition results of China's logistics industry. Without the introduction of energy and environmental factors, the average annual growth rate of TFP (TFPC) in China's logistics industry from 2003 to 2017 was $2.22 \%$, in which the average annual improvement rate of technical progress (TPC) was $2.85 \%$, while the average annual decrease rate of technical efficiency (TEC) was $0.61 \%$. After the introduction of energy and environment factors, the average annual growth rate of green TFP in the logistics industry dropped to $1.93 \%$, in which the average annual growth rate of technical progress declined to $2.1 \%$, and the average annual growth rate of technical efficiency was still negative, dropping by $0.16 \%$. Comparing the two sets of data, we can find that the growth rate of TFP in logistics industry and the growth rate of technical progress under the constraints of energy and environment are 0.29 and 0.75 percentage points lower than those without energy and 
TABle 2: Descriptive statistical results of input-output variables.

\begin{tabular}{|c|c|c|c|c|c|c|c|c|}
\hline Variable types & The variable name & Unit & $\begin{array}{l}\text { Sample } \\
\text { size }\end{array}$ & Mean & Median & $\begin{array}{l}\text { Standard } \\
\text { deviation }\end{array}$ & Minimum & Maximum \\
\hline $\begin{array}{l}\text { "Good" } \\
\text { output }\end{array}$ & Real added value & $\begin{array}{c}\text { One hundred million } \\
\text { yuan }\end{array}$ & 450 & 880.08 & 665.89 & 773.76 & 38.91 & 5141.41 \\
\hline "Bad" output & $\mathrm{CO}_{2}$ emissions & Ten thousand tons of & 450 & 1679.39 & 1377.87 & 1268.89 & 90.03 & 7958.30 \\
\hline \multirow{3}{*}{ Input } & $\begin{array}{c}\text { The number of } \\
\text { labor }\end{array}$ & Ten thousand people & 450 & 23.52 & 21.44 & 14.22 & 2.81 & 85.40 \\
\hline & The capital stock & $\begin{array}{c}\text { One hundred million } \\
\text { yuan }\end{array}$ & 450 & 3614.44 & 2813.75 & 2911.78 & 229.66 & 16844.09 \\
\hline & $\begin{array}{c}\text { Energy } \\
\text { consumption }\end{array}$ & Ten thousand tons of & 450 & 942.29 & 765.91 & 645.80 & 51.05 & 3495.89 \\
\hline
\end{tabular}

TABLE 3: TFP index of logistics industry and its decomposition (2003-2017).

\begin{tabular}{|c|c|c|c|c|c|c|}
\hline \multirow[t]{2}{*}{ Year } & \multicolumn{3}{|c|}{$\begin{array}{c}\text { Energy and environmental factors are not } \\
\text { introduced }\end{array}$} & \multicolumn{3}{|c|}{ Introduce energy and environmental factors } \\
\hline & TEC & TPC & TFPC & TEC & TPC & TFPC \\
\hline 2004 & 1.0076 & 1.0290 & 1.0368 & 0.9839 & 1.0057 & 0.9896 \\
\hline 2005 & 1.0105 & 1.0350 & 1.0459 & 1.0193 & 1.0179 & 1.0376 \\
\hline 2006 & 0.9930 & 1.0418 & 1.0344 & 1.0035 & 1.0266 & 1.0301 \\
\hline 2007 & 0.9963 & 1.0431 & 1.0392 & 1.0079 & 1.0297 & 1.0379 \\
\hline 2008 & 1.0178 & 1.0081 & 1.0261 & 0.9879 & 1.0270 & 1.0146 \\
\hline 2009 & 0.9813 & 1.0233 & 1.0042 & 0.9824 & 1.0572 & 1.0386 \\
\hline 2010 & 0.9793 & 1.0362 & 1.0148 & 0.9900 & 1.0106 & 1.0004 \\
\hline 2011 & 0.9897 & 1.0439 & 1.0332 & 0.9935 & 1.0138 & 1.0072 \\
\hline 2012 & 0.9925 & 1.0403 & 1.0325 & 1.0016 & 1.0051 & 1.0067 \\
\hline 2013 & 0.9347 & 1.0000 & 0.9347 & 0.9941 & 1.0008 & 0.9949 \\
\hline 2014 & 1.0017 & 1.0000 & 1.0017 & 1.0196 & 1.0070 & 1.0267 \\
\hline 2015 & 1.0212 & 1.0000 & 1.0212 & 0.9979 & 1.0274 & 1.0252 \\
\hline 2016 & 1.0314 & 1.0116 & 1.0434 & 1.0023 & 1.0386 & 1.0410 \\
\hline 2017 & 0.9624 & 1.0897 & 1.0487 & 0.9944 & 1.0277 & 1.0220 \\
\hline Mean & 0.9939 & 1.0285 & 1.0222 & 0.9984 & 1.0210 & 1.0193 \\
\hline
\end{tabular}

environment factors, respectively, while the growth rate of technical efficiency increased by 0.45 percentage points after the introduction of energy and environmental factors. However, the increase rate of technical efficiency cannot offset the negative impact of the decline rate of technical progress on TFP growth rate, and finally the Green TFP growth rate declined. It can be seen that China's logistics industry TFP estimation is influenced by energy and environment factors, and neglecting energy and environment factors will lead to an overestimation of TFP growth rate and technical progress growth rate.

From 2003 to 2017, green TFP and traditional TFP in China's logistics industry have positive growth trend in most years. Further analysis shows that the green TFP of the logistics industry increased negatively in 2004 and remained positive after 2005 (except for a slight decrease of $0.51 \%$ in 2013), which may be caused by the stricter policy of energy saving and consumption reduction during the 11th Five-Year Plan period and the 12th Five-Year Plan period. Both the 11th Five-Year Plan and the 12th Five-Year Plan emphasize the need to vigorously promote energy conservation and reduce consumption and reduce pollutant emissions. According to the outline of the 11th Five-Year Plan, China's total emission of major pollutants will be cut by $10 \%$ on the 2005 level. In 2008 , both TFP indexes showed a significant decline, indicating that the logistics industry has also been negatively impacted by the financial crisis [31]. From 2013 to 2015, the green TFP index was higher than the traditional TFP index. Combined with the research of Fare et al. [32], it shows that the reduction rate of "bad" output in China's logistics industry exceeds the growth rate of "good" output, and the environmental management efficiency of China's logistics industry has been improved, moving towards the direction of green growth.

According to the decomposition in terms of TFP index, the technical progress index in both cases is greater than 1 , while the technical efficiency index is less than 1 in most years, which means that the technical progress of logistics industry shows a continuous rising trend, but the technical efficiency fails to show an obvious growth pattern. It can be seen that, on the whole, technical progress is the main source of TFP growth in China's logistics industry, whether or not energy and environmental factors are introduced. This shows that China's logistics industry has not fully tapped the potential of existing resources and technologies, and there is still a great room to promote the performance growth of the logistics industry through efficiency improvement. 
3.2. Investigation of Regional Heterogeneity. In order to investigate the regional heterogeneity of TFP change in logistics industry, respectively, the country is divided into three areas (the east, central, and west) and the eight economic zones (the northeast economic zone, the northern coastal economic zone, the eastern coastal economic zone, the southern coastal economic zone, economic zone in the middle reaches of the Yellow River, the Yangtze River economic zone, the southwest economic zone, and the northwest economic zone) standard based on the division of the National Development and Reform Commission: the country is divided into the eastern region (including 11 provinces and cities, namely, Beijing, Shanghai, Tianjin, Hebei, Jiangsu, Zhejiang, Fujian, Shandong, Guangdong, Hainan, and Liaoning), the central region (including eight provinces, namely, Shanxi, Henan, Anhui, Jiangxi, Hubei, Hunan, Heilongjiang, and Jilin), and west (including 11 provinces, Inner Mongolia, Guangxi, Chongqing, Sichuan, Guizhou, Yunnan, Tibet, Shaanxi, Gansu, Qinghai, Ningxia, and Xinjiang). At the same time, we drew lessons from the criteria in the report strategies and Policies for Coordinated Regional Development released by the Development Research Center of the State Council to the national integrated into the northeast economic zone (including Heilongjiang, Liaoning, and Jilin), the northern coastal economic zone (including Shandong, Hebei, Beijing, and Tianjin), east coastal economic zone (including Jiangsu, Zhejiang, and Shanghai), southern coastal economic zone (including Guangdong, Fujian, and Hainan), economic zone in the middle reaches of the Yellow River (including Inner Mongolia, Henan, Shanxi, and Shaanxi), economic zone in the middle reach of Yangtze River (including Anhui, Jiangxi, Hunan, and Hubei), southwest economic zone (including Guangxi, Sichuan, Chongqing, Guizhou, and Yunnan), and the northwest zone (including Qinghai, Gansu, Ningxia, and Xinjiang). Because of the availability of data, the above two categories do not include Xizang. It can be seen from Table 4 that the two types of TFP indexes and their decomposition in China's logistics industry have great regional differences.

Under the three regional classification standards, without the introduction of energy and environmental factors, the regional ranking of average annual growth rate of TFP in the logistics industry from high to low is in the western, eastern, and central regions. After the introduction of energy and environmental factors, it follows the eastern, western, and central regions. The growth rate of green TFP in the eastern region is higher than that in the central and western regions, which is closely related to the relatively developed economy and natural geographical advantages of the eastern region. In addition, the eastern region pays more attention to the introduction of talents and invests more in the research and development of clean technology and environmental protection technology [31]. The growth rate of green TFP in central region is lower than that in western region, mainly due to the lower growth rate of technical progress in central region. The relative rank of TFP index ( TFPR ) in each region will be affected by energy and environment factors, so failure to take energy and environment factors into account will misjudge the relative level of green growth performance in each region. In addition, regardless of the introduction of energy and environmental factors, technical progress is the main driving factor for the growth of TFP in the logistics industry in each region, and the technical efficiency has a negative impact on the growth of TFP.

Under the eight regional classification standards, when energy and environmental factors are not taken into account, the regional ranking of the average annual growth rate of TFP in the logistics industry from high to low is the eastern coastal economic zone, the southwest region, the middle reaches of the Yangtze River, the middle reaches of the Yellow River, the northwest region, the southern coastal region, the northern coastal region, and the northeast economic zone. After considering the energy and environment factors, the TFP growth rate of the eastern coastal economic zone still ranks the first, followed by the southern coastal region, the northern coastal region, the northeast region, the middle reaches of the Yellow River, the southwest region, the middle reaches of the Yangtze River, and the northwest region. It can be seen that, after the introduction of energy and environment factors, the ranking of TFP of various economic zones has changed again. The logistics industry in the southwest region, the middle reach of the Yangtze River, and the northwest region is more constrained by energy and environmental factors, and the TFP index and its ranking drop significantly. The traditional TFP index in most areas is larger than the green TFP index, which again indicates that if energy and environmental factors are ignored, the measurement results will deviate from the actual situation. In addition, regardless of the introduction of energy and environmental factors, the main driving factor of TFP growth in each region is technical progress, which is consistent with the research conclusions of the three regions.

3.3. Investigation of Interprovincial Heterogeneity. Table 5 reports the TFP index and its decomposition results of logistics industry in various provinces of China. It can be found that the TFP index of China's logistics industry has great interprovincial differences. Without the introduction of energy and environmental factors, the fastest growth rate of TFP was in Yunnan province, followed by Zhejiang and Inner Mongolia, and the lowest growth rate was in Liaoning (with an average annual decrease of 2.67\%). After the introduction of energy and environment factors, the province with the highest TFP growth rate was Zhejiang, followed by Jiangsu and Guangdong, and the lowest growth rate was Chongqing (with an average annual decrease of $0.46 \%$ ). From the numerical comparison of TFP index, after the introduction of energy and environment factors, there are 15 provinces (Beijing, Tianjin, Shanxi, Liaoning, Jilin, Heilongjiang, Shanghai, Hubei, Guangdong, Guangxi, Hainan, Chongqing, Shaanxi, Gansu, and Ningxia) of TFP index which rose, the TFP index rank also has some promotion mostly (except in Guangxi, Ningxia, and Chongqing).

From the decomposition of the TFP index, the technical progress of logistics industry in most provinces contributes more to the TFP index. When the energy and 
TABLE 4: Mean of national and regional TFP index and its decomposition terms (2003-2017).

\begin{tabular}{|c|c|c|c|c|c|c|}
\hline \multirow[t]{2}{*}{ Province } & \multicolumn{3}{|c|}{$\begin{array}{l}\text { Energy and environmental factors are not } \\
\text { introduced }\end{array}$} & \multicolumn{3}{|c|}{ Introduce energy and environmental factors } \\
\hline & TEC & TPC & TFPC & TEC & TPC & TFPC \\
\hline National average & 0.9939 & 1.0285 & 1.0222 & 0.9984 & 1.0210 & 1.0193 \\
\hline Eastern & 0.9938 & 1.0283 & 1.0220 & 1.0037 & 1.0226 & 1.0264 \\
\hline Central & 0.9979 & 1.0148 & 1.0127 & 0.9984 & 1.0145 & 1.0128 \\
\hline Western & 0.9895 & 1.0379 & 1.0270 & 0.9918 & 1.0235 & 1.0151 \\
\hline Northeast & 0.9818 & 1.0059 & 0.9876 & 1.0059 & 1.0124 & 1.0184 \\
\hline Northern coast & 0.9932 & 1.0205 & 1.0135 & 1.0013 & 1.0211 & 1.0225 \\
\hline East coast & 1.0122 & 1.0431 & 1.0559 & 1.0093 & 1.0308 & 1.0403 \\
\hline Southern coast & 0.9847 & 1.0323 & 1.0165 & 1.0050 & 1.0210 & 1.0261 \\
\hline Mid- Yellow River & 1.0022 & 1.0228 & 1.0250 & 0.9988 & 1.0178 & 1.0166 \\
\hline Mid-Yangtze River & 1.0054 & 1.0229 & 1.0284 & 0.9968 & 1.0175 & 1.0143 \\
\hline Southwest & 0.9846 & 1.0446 & 1.0285 & 0.9901 & 1.0247 & 1.0146 \\
\hline Northwest & 0.9893 & 1.0310 & 1.0199 & 0.9883 & 1.0220 & 1.0100 \\
\hline
\end{tabular}

TABLE 5: TFP Index and its decomposition of logistics industry in all provinces of China (2003-2017).

\begin{tabular}{|c|c|c|c|c|c|c|c|c|}
\hline \multirow[t]{2}{*}{ Province } & \multicolumn{4}{|c|}{$\begin{array}{c}\text { Energy and environmental factors are not } \\
\text { introduced }\end{array}$} & \multicolumn{4}{|c|}{ Introduce energy and environmental factors } \\
\hline & TEC & TPC & TFPC & TFPR & TEC & TPC & TFPC & TFPR \\
\hline Beijing & 0.9764 & 1.0020 & 0.9784 & 28 & 1.0000 & 1.0173 & 1.0173 & 17 \\
\hline Tianjin & 1.0063 & 1.0183 & 1.0247 & 13 & 1.0147 & 1.0201 & 1.0350 & 4 \\
\hline Hebei & 1.0000 & 1.0442 & 1.0442 & 9 & 1.0000 & 1.0321 & 1.0321 & 7 \\
\hline Shanxi & 0.9904 & 1.0048 & 0.9952 & 26 & 1.0001 & 1.0103 & 1.0104 & 23 \\
\hline Inner Mongolia & 1.0134 & 1.0594 & 1.0736 & 3 & 1.0017 & 1.0308 & 1.0325 & 6 \\
\hline Liaoning & 0.9697 & 1.0036 & 0.9733 & 30 & 0.9926 & 1.0092 & 1.0018 & 28 \\
\hline Jilin & 0.9876 & 1.0115 & 0.9990 & 23 & 1.0069 & 1.0156 & 1.0226 & 12 \\
\hline Heilongjiang & 0.9882 & 1.0026 & 0.9908 & 27 & 1.0185 & 1.0123 & 1.0310 & 8 \\
\hline Shanghai & 1.0221 & 1.0096 & 1.0319 & 11 & 1.0173 & 1.0156 & 1.0332 & 5 \\
\hline Jiangsu & 1.0193 & 1.0402 & 1.0602 & 5 & 1.0056 & 1.0309 & 1.0368 & 2 \\
\hline Zhejiang & 0.9956 & 1.0808 & 1.0760 & 2 & 1.0049 & 1.0459 & 1.0511 & 1 \\
\hline Anhui & 0.9924 & 1.0194 & 1.0117 & 17 & 0.9913 & 1.0201 & 1.0112 & 20 \\
\hline Fujian & 0.9831 & 1.0715 & 1.0534 & 7 & 1.0000 & 1.0306 & 1.0306 & 9 \\
\hline Jiangxi & 1.0183 & 1.0376 & 1.0567 & 6 & 0.9982 & 1.0192 & 1.0174 & 16 \\
\hline Shandong & 0.9901 & 1.0181 & 1.0081 & 18 & 0.9908 & 1.0152 & 1.0058 & 26 \\
\hline Henan & 1.0138 & 1.0162 & 1.0302 & 12 & 0.9890 & 1.0137 & 1.0025 & 27 \\
\hline Hubei & 0.9939 & 1.0118 & 1.0056 & 20 & 1.0044 & 1.0130 & 1.0175 & 15 \\
\hline Hunan & 1.0174 & 1.0228 & 1.0406 & 10 & 0.9934 & 1.0179 & 1.0111 & 21 \\
\hline Guangdong & 0.9862 & 1.0124 & 0.9984 & 25 & 1.0130 & 1.0220 & 1.0353 & 3 \\
\hline Guangxi & 0.9803 & 1.0222 & 1.0021 & 22 & 0.9935 & 1.0176 & 1.0111 & 22 \\
\hline Hainan & 0.9848 & 1.0141 & 0.9987 & 24 & 1.0021 & 1.0104 & 1.0125 & 19 \\
\hline Chongqing & 0.9606 & 1.0164 & 0.9764 & 29 & 0.9777 & 1.0181 & 0.9954 & 30 \\
\hline Sichuan & 0.9757 & 1.0421 & 1.0168 & 15 & 0.9854 & 1.0225 & 1.0076 & 24 \\
\hline Guizhou & 1.0058 & 1.0585 & 1.0647 & 4 & 0.9982 & 1.0316 & 1.0298 & 10 \\
\hline Yunnan & 1.0013 & 1.0851 & 1.0865 & 1 & 0.9959 & 1.0336 & 1.0294 & 11 \\
\hline Shaanxi & 0.9915 & 1.0115 & 1.0029 & 21 & 1.0044 & 1.0166 & 1.0211 & 13 \\
\hline Gansu & 0.9976 & 1.0083 & 1.0059 & 19 & 1.0017 & 1.0140 & 1.0156 & 18 \\
\hline Qinghai & 0.9747 & 1.0714 & 1.0443 & 8 & 0.9638 & 1.0364 & 0.9989 & 29 \\
\hline Ningxia & 0.9909 & 1.0270 & 1.0176 & 14 & 0.9934 & 1.0250 & 1.0182 & 14 \\
\hline Xinjiang & 0.9941 & 1.0184 & 1.0123 & 16 & 0.9948 & 1.0128 & 1.0075 & 25 \\
\hline Mean & 0.9939 & 1.0285 & 1.0222 & & 0.9984 & 1.0210 & 1.0193 & \\
\hline
\end{tabular}

environmental factors are not taken into account, only Shanghai's growth rate of technical efficiency is higher than that of technical progress. After accounting for energy and environmental factors, the number of provinces where technical efficiency has grown faster than technical progress has risen to two, namely, Shanghai and Heilongjiang. This shows that, in the vast majority of provinces, through improving technical efficiency to further enhance the logistics industry productivity, there is a large space. 
TABLE 6: Robustness tests of two kinds of TFP index measurement results.

\begin{tabular}{|c|c|c|c|c|c|}
\hline \multirow[t]{2}{*}{ Depreciation rate (\%) } & \multirow[t]{2}{*}{ Index indicator } & \multicolumn{2}{|c|}{$\begin{array}{l}\text { Energy and environmental } \\
\text { factors are not introduced }\end{array}$} & \multicolumn{2}{|c|}{$\begin{array}{l}\text { Introduce energy and } \\
\text { environmental factors }\end{array}$} \\
\hline & & Method 1 & Method 2 & Method 1 & Method 2 \\
\hline \multirow{3}{*}{6.0} & $\mathrm{EC}$ & 0.9939 & 0.9936 & 0.9984 & 0.9984 \\
\hline & $\mathrm{TC}$ & 1.0285 & 1.0271 & 1.0210 & 1.0206 \\
\hline & TFPC & 1.0222 & 1.0205 & 1.0193 & 1.0190 \\
\hline \multirow{3}{*}{4.0} & EC & 0.9943 & 0.9939 & 0.9984 & 0.9984 \\
\hline & $\mathrm{TC}$ & 1.0273 & 1.0261 & 1.0208 & 1.0205 \\
\hline & TFPC & 1.0214 & 1.0198 & 1.0192 & 1.0189 \\
\hline \multirow{3}{*}{9.6} & EC & 0.9936 & 0.9932 & 0.9979 & 0.9984 \\
\hline & $\mathrm{TC}$ & 1.0302 & 1.0287 & 1.0215 & 1.0209 \\
\hline & TFPC & 1.0237 & 1.0218 & 1.0194 & 1.0192 \\
\hline
\end{tabular}

3.4. Robustness Test of TFP Results. To investigate the influence of the capital depreciation rate and base year capital stock on the calculation results, we make a robust analysis by changing the capital depreciation rate and the estimation method of the base year capital stock. The specific measures are as follows: first, keeping the depreciation rate unchanged (6\%) and adopting the base year capital stock estimation method of Hall and Jones [33] (Method 2 in Table 6); secondly, keeping the estimation method of the base year capital stock unchanged (method 1 in Table 6), and setting the depreciation rate as $4 \%$ in $\mathrm{Wu}$ [28] and 9.6\% in Zhang [34], respectively; finally, changing the depreciation rate and the estimation method of the base year capital stock simultaneously. The measurement results of all combinations are listed in Table 6. Due to space limitation, only the average results for various combinations are given here. According to the average value and the specific results of each province and year, after changing the capital depreciation rate and the estimation method of the base year capital stock, the results only change slightly in the specific value, but these changes do not change the basic conclusion of this paper. Therefore, the results of this paper are robust.

3.5. Analysis of the Evolution Trend of Regional Differences. Since green TFP can better reflect the green growth performance of the logistics industry, we only analyze the regional variation trend of green TFP. Referring to the practice of Rezitis [35] and Teng et al. [4], we use the variable coefficient to measure the degree of regional difference, and the formula is as follows:

$$
\begin{aligned}
& S=\sqrt{\frac{\left[\sum_{i}\left(\mathrm{TFP}_{i t}-t f p_{t}\right)^{2}\right]}{N},} \\
& V=\frac{S}{t f p_{t}},
\end{aligned}
$$

where $S$ represents the standard deviation, $\mathrm{TFP}_{i t}$ represents the green TFP of the logistics industry of $i$ province in the $t$ year, $t f p_{t}$ represents the average value of the $t$ year green TFP of the sample provinces, $N$ represents the number of provinces, and $V$ represents the variation coefficient of TFP.
Figure 1 depicts the evolution characteristics of regional difference degree of green TFP index of logistics industry in the whole sample and the three regions of east, middle, and west. It can be found that the regional difference degree of green TFP in the national logistics industry generally decreases with the passage of time, which means that the green TFP in the national logistics industry may have $\sigma$ convergence on the whole. In terms of the evolution of the internal differences of green TFP in the three regions, the differences of green TFP in the eastern, central, and western regions show a decreasing trend on the whole, and the evolution trajectory is consistent with the national samples, indicating that the differences of green TFP in each region is shrinking, and there may also exist a $\sigma$ convergence. The mean value of the variation coefficient from high to low is in western, eastern, and central regions. From the perspective of interregional differences, the difference of variation coefficient among the three regions in 2017 is greater than that in 2004, indicating that the interregional differences are expanding.

According to the variation of the degree of difference of green TFP in the eight economic zones (Figure 2), similar to the situation in the whole sample and the eastern, central, and western regions, the variation coefficient of most economic zones also shows a decreasing trend, and there may be a $\sigma$ convergence. Specifically, in 2017, the variation coefficients of the eastern coast, the southern coast, the middle reaches of Yangtze River, the middle reaches of the Yellow River, the southwest, and the northwest area relative to the variation coefficient of 2004 decreased by $81.7 \%, 89.2 \%$, $85.5 \%, 76.9 \%, 84.5 \%$, and $10 \%$. Thus, the largest decline was in the southern coastal areas, while the smallest decline was in the northwest region, indicating that the differences of green TFP index among the provinces in these economic zones are narrowing. In 2017, the variation coefficient in northeast China and the northern coastal economic zone increased by $11.3 \%$ and $286.3 \%$, respectively, compared with 2004, indicating that the internal differences between the two regions are continuously expanding. Comparing with the mean value of the variation coefficient of green TFP, we can find that the difference of green TFP among the provinces in the middle reaches of the Yellow River economic zone is the greatest. 


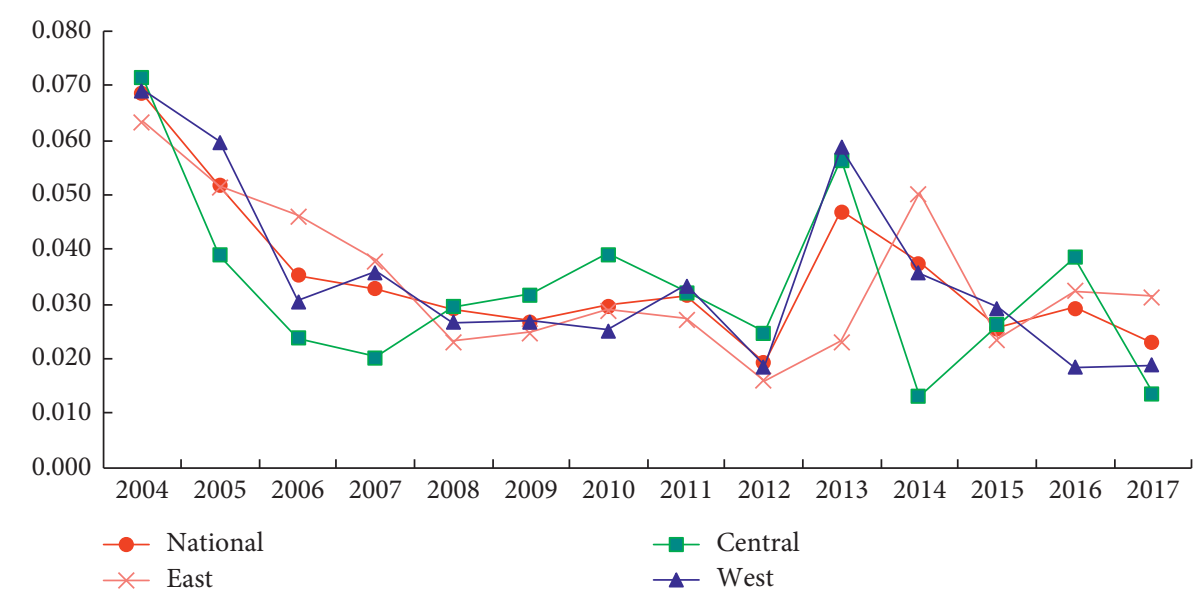

FIGURE 1: The change trend of regional differences in green TFP of logistics industry in China and three regions.

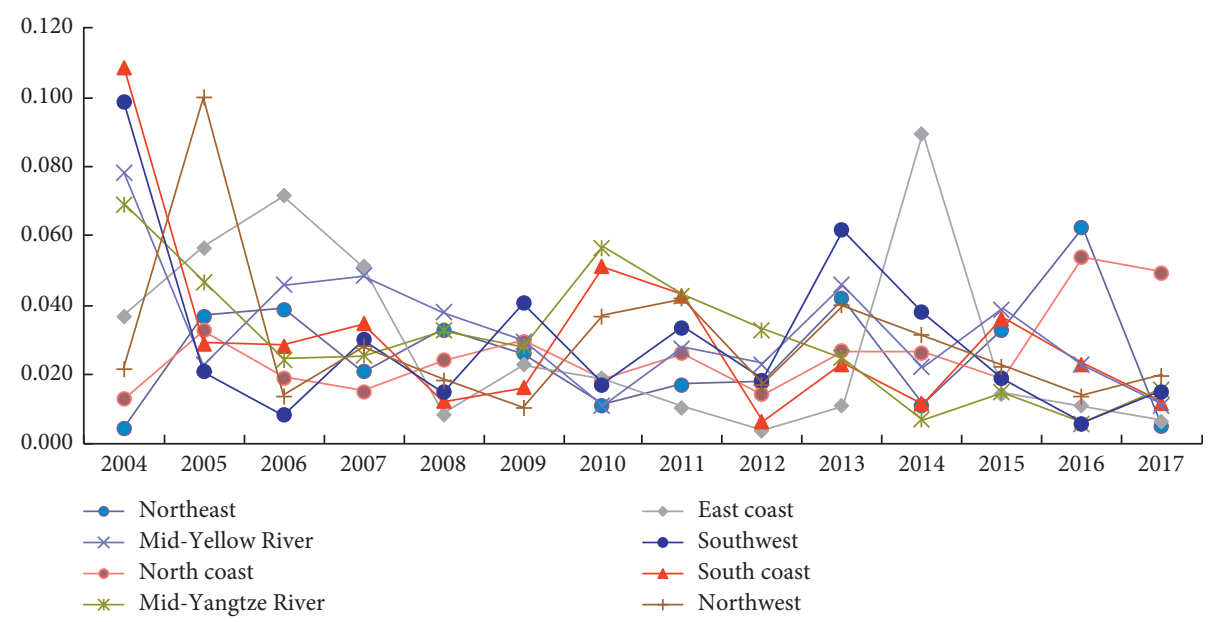

Figure 2: Variation trend of regional differences in green TFP of logistics industry in the eight economic zones.

\section{Conclusions}

This paper introduces the energy and environmental factors into the TFP measurement framework of China's logistics industry and compares it with the traditional TFP without considering energy and environmental factors. The main conclusions are as follows.

First, the green TFP and traditional TFP of China's logistics industry are both on the rise, with an average annual growth rate of $1.93 \%$ and $2.22 \%$, respectively. It can be seen that the absence of energy and environmental factors will lead to the overestimation of TFP of the logistics industry, and energy and environmental factors will have a significant impact on the TFP estimation of the logistics industry. Whether green TFP or traditional TFP, the main source of its growth is technical progress, and there is still much room for further enhancing the TFP in the logistics industry through the improvement of technical efficiency.

Second, the growth of green TFP in China's logistics industry has great regional heterogeneity. Under the three regional division standards, the average annual growth rate of green TFP is from high to low in the eastern, western, and central regions. Under the eight regional classification standards, the average annual growth rate of green TFP is successively from high to low in the eastern coastal economic zone, the southern coastal zone, the northern coastal zone, the northeast region, the middle reaches of the Yellow River, the southwest region, middle reaches of the Yangtze River, and the northwest region. The logistics industry in the southwest region, the middle reach of the Yangtze River, and the northwest region is more constrained by energy and environmental factors, and its TFP index and ranking decline significantly after considering energy and environmental factors.

Third, the growth of green TFP in China's logistics industry has great interprovincial heterogeneity. The province with the highest growth rate of green TFP is Zhejiang, followed by Jiangsu and Guangdong, and the slowest growth rate is Chongqing, with an average annual decrease of $0.46 \%$. From the perspective of the decomposition term of the green TFP index, the technical progress of the logistics industry in most provinces contributes more to the green TFP index, indicating that there is a large space for the vast majority of provinces to further improve the green 
productivity of logistics industry by improving the technical efficiency.

Fourth, from the evolution trend of the internal differences of green TFP in the logistics industry of the three regions, the regional differences of green TFP in the east, the middle, and the west are generally decreasing, and the evolution trajectory is consistent with the national samples, indicating that the differences of green TFP in the logistics industry within each region are shrinking, and there may be $\sigma$ convergence. However, from the perspective of the differences among the three regions, the difference of the variation coefficient among the three regions in 2017 is greater than that in 2004, indicating that the differences among the three regions are expanding. From the results of the eight economic regions, the variation coefficients of most economic regions also show a downward trend.

Based on the above conclusions, the main implications are as follows: firstly, in the context of China's supply-side structural reforms and the concept of green development, we should pay more attention to the role of logistics industry TFP (especially green TFP) in the green growth and sustainable development of the logistics industry, to promote the growth pattern of China's logistics industry from factordriven to green TFP-drive, to further promote the development of green logistics. Secondly, while maintaining the contribution level of technical progress to TFP of logistics industry, we can further focus on improving technical efficiency of logistics industry to promote the growth of green TFP. Thirdly, the government can formulate regional difference policies to promote the growth of green TFP and the development of green logistics according to the factor endowments of different regions. By promoting the introduction, $R \& D$, and application of green and low-carbon technologies, the government can strengthen the regional exchanges and cooperation on green technologies to gradually reduce the regional differences in the growth of green TFP in the logistics industry. Fourthly, the efficiency of R\&D innovation in transforming scientific and technological achievements into final productivity is low due to some problems in the use of $\mathrm{R} \& \mathrm{D}$ expenditure in logistics industry in China. Therefore, it is necessary to pay attention to the structure of $R \& D$ investment in the use of logistics $R \& D$ expenses to prevent the phenomenon of industry university research disconnection in the future. Fifthly, under the constraints of energy and environmental factors, in order to improve the green TFP of China's logistics industry, how to achieve $\mathrm{CO}_{2}$ emission reduction without damaging economic benefits needs to be paid more attention. This requires that the proportion of high carbon energy consumption must be reduced as far as possible, such as vigorously developing new energy, improving energy utilization efficiency, and product innovation, so as to fundamentally promote the green TFP growth of China's logistics industry. Finally, it should be pointed out that although we have carefully studied the change trend of green productivity and the interprovincial and regional differences in China's logistics industry by using existing methods, due to careful consideration, deeper reasons and policy interpretation are yet to be further analyzed in the future.

\section{Data Availability}

The data that support the findings of this study are openly available in China Statistical Yearbook and China Energy Statistical Yearbook at http://www.stats.gov.cn/tjsj.

\section{Conflicts of Interest}

The authors declare no conflicts of interest.

\section{Acknowledgments}

This work was funded by the Key Projects of National Natural Science Foundation of China (Nos. 71803197 and 71503273), Ministry of Education Humanities and Social Sciences Foundation (Nos. 18YJC630094 and 14YJC790046), Fundamental Research Funds for the Central Universities (No. 31511910801), and Soft Science Project of Technological Innovation in Hubei Province (No. 2019ADC029).

\section{References}

[1] M. C. Strazicich and J. A. List, "Are $\mathrm{CO}_{2}$ emission levels converging among industrial countries?" Environmental and Resource Economics, vol. 24, no. 3, pp. 263-271, 2003.

[2] J. Westerlund and S. A. Basher, "Testing for convergence in carbon dioxide emissions using a century of panel data," Environmental and Resource Economics, vol. 40, no. 1, pp. 109-120, 2008.

[3] A. Omri, D. K. Nguyen, and C. Rault, "Causal interactions between $\mathrm{CO}_{2}$ emissions, FDI, and economic growth: evidence from dynamic simultaneous-equation models," Economic Modelling, vol. 42, pp. 382-389, 2014.

[4] Z. W. Teng, Z. B. Hu, and X. Y. Jiang, "Study on the difference and convergence of carbon productivity in China's service industry," The Journal of Quantitative and Technical Economics, vol. 34, no. 3, pp. 78-94, 2017.

[5] K. Matthews and N. Zhang, "Bank productivity in China 1997-2007: measurement and convergence," China Economic Review, vol. 21, no. 4, pp. 617-628, 2010.

[6] S. M. Miller and M. P. Upadhyay, "Total factor productivity and the convergence hypothesis," Journal of Macroeconomics, vol. 24, no. 2, pp. 267-286, 2002.

[7] E. van der Marel, "Trade in services and TFP: the role of regulation," The World Economy, vol. 35, no. 11, pp. 1530-1558, 2012.

[8] X. Y. Jing, Q. M. Tan, and J. X. Zhu, “An empirical analysis on total factor productivity diversity in China's transportation industry," Henan Science, vol. 30, no. 9, pp. 1359-1364, 2012.

[9] Y. Chen, "Efficiency analysis of China's transportation, storage and postal service-based on Malmquist productivity function," Journal of Chongqing Jiaotong University (Social Science Edition), vol. 12, no. 4, pp. 49-52, 2012.

[10] Y. S. Jiang, X. F. Ji, and J. M. Li, "Energy efficiency evaluation of logistics industry in China under low-carbon constraints," Journal of Wuhan University of Technology (Transportation Science \& Engineering), vol. 43, no. 2, pp. 291-295, 2019.

[11] D. Yuan, H. Z. Lei, W. Huang, and Y. He, "Research on the heterogeneity and convergence of total factor productivity in Chinese producer service," Soft Science, vol. 29, no. 6, pp. 24-27, 2015. 
[12] T. Xiao, "A comparative analysis of total factor productivity dynamic change and convergence of Chinese tertiary industry's sub-sectors," Management Review, vol. 29, no. 8, pp. 53-64, 2017.

[13] Y. H. Chung, R. Färe, and S. Grosskopf, "Productivity and undesirable outputs: a directional distance function approach," Journal of Environmental Management, vol. 51, no. 3, pp. 229-240, 1997.

[14] K. Tone, "A slacks-based measure of efficiency in data envelopment analysis," European Journal of Operational Research, vol. 130, no. 3, pp. 498-509, 2001.

[15] M. Watanabe and K. Tanaka, "Efficiency analysis of Chinese industry: a directional distance function approach," Energy Policy, vol. 35, no. 12, pp. 6323-6331, 2007.

[16] B. Wang, Y. R. Wu, and P. F. Yan, "Environmental efficiency and environmental total factor productivity growth in China's regional economies," Economic Research Journal, vol. 45, no. 5, pp. 95-109, 2010.

[17] H. Fukuyama and W. L. Weber, "A directional slacks-based measure of technical inefficiency," Socio-Economic Planning Sciences, vol. 43, no. 4, pp. 274-287, 2009.

[18] D.-h. Oh, "A metafrontier approach for measuring an environmentally sensitive productivity growth index," Energy Economics, vol. 32, no. 1, pp. 146-157, 2010.

[19] B. W. Ang, "Decomposition analysis for policymaking in energy:", Energy Policy, vol. 32, no. 9, pp. 1131-1139, 2004.

[20] B. W. Ang and N. Liu, "Handling zero values in the logarithmic mean Divisia index decomposition approach," Energy Policy, vol. 35, no. 1, pp. 238-246, 2007.

[21] M. Zhang, H. Mu, Y. Ning, and Y. Song, "Decomposition of energy-related $\mathrm{CO}_{2}$ emission over 1991-2006 in China," Ecological Economics, vol. 68, no. 7, pp. 2122-2128, 2009.

[22] M. Zhang, X. Liu, W. Wang, and M. Zhou, "Decomposition analysis of $\mathrm{CO}_{2}$ emissions from electricity generation in China," Energy Policy, vol. 52, pp. 159-165, 2013.

[23] W. Wang, X. Liu, M. Zhang, and X. Song, "Using a new generalized LMDI (logarithmic mean Divisia index) method to analyze China's energy consumption," Energy, vol. 67, no. 1, pp. 617-622, 2014.

[24] M. Zhang, Y. Song, B. Su, and X. Sun, "Decomposing the decoupling indicator between the economic growth and energy consumption in China," Energy Efficiency, vol. 8, no. 6, pp. 1231-1239, 2015.

[25] A. C. Harberger, "Perspective on capital and technology in less developed countries," in Contemporary Economic Analysis, M. J. Artis and A. R. Nobay, Eds., pp. 69-151, Croom Helm, London, UK, 1978.

[26] J.-W. Lee and K. Hong, "Economic growth in Asia: determinants and prospects," Japan and the World Economy, vol. 24, no. 2, pp. 101-113, 2012.

[27] R. J. Barro and J.-W. Lee, "A new data set of educational attainment in the world, 1950-2010," NBER Working Paper, National Bureau Of Economic Research, no. 15902, Cambridge, MA, USA, 2010.

[28] Y. R. Wu, "China's capital stock series by region and sector," University of Western Australia, Perth, Australia, Discussion Paper, 2009.

[29] J. T. Fox and V. Smeets, "Does input quality drive measured differences in firm productivity?" International Economic Review, vol. 52, no. 4, pp. 961-989, 2011.

[30] J. Zheng, A. Bigsten, and A. Hu, "Can China's growth be sustained? A productivity perspective," World Development, vol. 37, no. 4, pp. 874-888, 2009.
[31] S. L. Wang, Z. W. Teng, and J. Liu, "The disparity and convergence of TFP change in China's service industry-based on regional and industry perspectives," Economic Research Journal, vol. 50, no. 8, pp. 73-84, 2015.

[32] R. Färe, S. Grosskopf, and C. A. Pasurka Jr., "Accounting for air pollution emissions in measures of state manufacturing productivity growth," Journal of Regional Science, vol. 41, no. 3, pp. 381-409, 2001.

[33] R. E. Hall and C. I. Jones, "Why do some countries produce so much more output per worker than others?" The Quarterly Journal of Economics, vol. 114, no. 1, pp. 83-116, 1999.

[34] J. Zhang, "Estimation of China's provincial capital stock (1952-2004) with applications," Journal of Chinese Economic and Business Studies, vol. 6, no. 2, pp. 177-196, 2008.

[35] A. N. Rezitis, "Agricultural productivity and convergence: europe and the United States," Applied Economics, vol. 42, no. 8, pp. 1029-1044, 2010. 